\title{
PENGARUH STRATEGI PEMASARAN, PELAYANAN DAN HARGA TERHADAP KEPUTUSAN PEMBELIAN TIKET PESAWAT TERBANG
}

\author{
Anthony Christino ${ }^{1}$ \\ Feby Erya ${ }^{2}$ \\ Hendry ${ }^{3}$ \\ Cindy Evelyn Lovencia ${ }^{4}$
}

\author{
1,2,3,4Fakultas Ekonomi S1 Manajemen Universitas Prima Indonesia Sumatera \\ Utara, Indonesia \\ email: antony_phanz@yahoo.com
}

\begin{abstract}
ABSTRAK
Penelitian ini bertujuan menganalisis pengaruh strategi pemasaran, pelayanan dan harga terhadap keputusan pembelian tiket pesawat terbang pada PT Duta Megah Wisata. Penelitian ini menggunakan pendekatan kuantitatif dan jenis data kuantitatif. Sumber data yang digunakan data primer yang langsung dari perusahaan dan data sekunder yang menggunakan literatur buku dan jurnal. Populasi ialah konsumenPT Duta Megah Wisata berjumlah 133 penelitian dengan sampel sebanyak 100 responden. Uji Asumsi klasik diperlukan agar analisis data regresi linier berganda tidak bias. Hasil penelitian yang menjadi kesimpulan adalah strategi pemasaran berpengaruh positif terhadap keputusan pembelian tiket pesawat terbang pada PT Duta Megah Wisata. Pelayanan berpengaruh positif terhadap keputusan pembelian tiket pesawat terbang pada PT Duta Megah Wisata. Harga berpengaruh positif terhadap keputusan pembelian tiket pesawat terbang pada PT Duta Megah Wisata. Strategi pemasaran, pelayanan dan harga berpengaruh secara simultan terhadap keputusan pembelian tiket pesawat terbang Pada PT Duta Megah Wisata.
\end{abstract}

Kata Kunci :strategi pemasaran, pelayanan, harga dan keputusan pembelian.

\begin{abstract}
The aim is to analyze the effect of marketing, service and price strategies on the decision to buy airplane tickets at PT Duta Megah Wisata. The quantitative approach used. The type of data is quantitative data. Data sources are primary data and secondary data. The population is the consumers of PT Duta Megah Wisata totaling 133 studies with a sample of 100 respondents. Analysis of multiple linear regression data previously carried out classical assumptions. The result of the research that becomes the conclusion is that the marketing strategy has a influence on the decision to purchase airplane tickets at PT Duta Megah Wisata. Services influence in purchasing decisions for airplane tickets at PT Duta Megah Wisata. Prices influence on the decision to buy airplane tickets at PT Duta Megah Wisata. Marketing, service and price strategies influence simultaneously on the decision to purchase airplane tickets at PT Duta Megah Wisata.

Keywords: marketing strategy, service, price and purchase decisions.
\end{abstract}




\section{PENDAHULUAN}

Industri travel menjadi semakin kompetitif seiring dengan tumbuhnya wisatawan luar negeri yang berkunjung ke Indonesia. Sekarang ini, agen travel yang semakin banyak sehingga konsumen sangat mudah untuk memperoleh tiket yang diinginkan. Untuk memenuhi permintaan konsumen di kota Medan, agen travel yang cukup dikenal konsumen salah satunya adalah PT Duta Megah Wisata. PT Duta Megah Wisata termasuk perusahaan jasa yang menyediakan tiket pesawat terbang dan paket perjalanan (tour). Wilayah pemasaran yang dilakukan PT Duta Megah Wisata hanya berada di Kota Medan.Dengan ada banyaknya persaingan di kota Medan tentu tidak membuat PT Duta Megah Wisata hanya melayani konsumen pada toko fisik (offline) saja. Dengan memudahkan pembelian konsumen dalam membeli tiket pesawat terbang, PT Duta Megah Wisata memberikan fasilitas pelayanan secara daring (online).

Berdasarkan survei awal, padadata tahun 2018 PT Duta Megah Wisata mengalami penurunan penjualan yang dikarenakan permintaan tiket pesawat terbangyang menurun.

Tabel 1.

Target dan Realisasi Penjualan Bulan Januari S/d Desember 2018

\begin{tabular}{lccc}
\hline \multicolumn{1}{c}{ Bulan } & $\begin{array}{c}\text { Target Penjualan } \\
(\mathrm{Rp})\end{array}$ & $\begin{array}{c}\text { Realisasi Penjualan } \\
(\mathrm{Rp})\end{array}$ & $\begin{array}{c}\text { Persentase } \\
(\%)\end{array}$ \\
\hline Januari & 800.000 .000 & 650.450 .000 & 81,31 \\
Februari & 800.000 .000 & 635.775 .000 & 79,47 \\
Maret & 800.000 .000 & 625.550 .000 & 78,19 \\
April & 800.000 .000 & 500.000 .000 & 62,50 \\
Mei & 800.000 .000 & 475.850 .000 & 59,48 \\
Juni & 800.000 .000 & 615.800 .000 & 76,98 \\
Juli & 800.000 .000 & 608.000 .000 & 76,00 \\
Agustus & 800.000 .000 & 535.045 .000 & 66,88 \\
September & 800.000 .000 & 515.000 .000 & 64,38 \\
Oktober & 800.000 .000 & 498.775 .000 & 62,35 \\
November & 800.000 .000 & 457.850 .000 & 57,23 \\
Desember & 800.000 .000 & 407.335 .000 & 50,92 \\
\hline
\end{tabular}

Sumber: Data diolah, 2020

Berdasarkan Tabel 1. terlihat terjadi penurunan penjualan diakibatkan oleh pilihan produk, strategi pemasaran dan harga produk. Jika dilihat pilihan produk, konsumen dengan sangat mudah membandingkan produk yang dijual pada perusahaan travel sejenisnya, sehingga daya beli tiket pesawat pada PT Duta Megah Wisata menurun. Jika dilihat dari strategi pemasaran yang dilakukan PT Duta Megah Wisatamencakup promosi iklan masih rendah, distribusi tiket pesawat terbang hanya berada di Kota Medan dan sekitarnya, serta fasilitas penjualan perusahaan belum maksimal, seperti kesederhanaan fasilitas perusahaan dalam 
memasarkan tiket pesawat terbang tersebut mengakibatkan konsumenkurang berminat.

Jika dilihat berdasarkan harga, harga memainkan peranan penting dalam penjualan tiket pesawat terbang. Harga tiket pesawat terbang beraneka ragamdan banyak variasinya dengan berbagai jenis pesawat terbang. Harga tiket pesawat terbang yang dijual perusahaan lebih mahal dari travel lain disebabkan perusahaan menyediakan antar tiket hingga ke bandara, kantor dan rumah konsumen. Fasilitas pengantaran tiket pesawat terbang ini ke konsumen telah diperhitungkan harga sehingga bagi konsumen yang datang mengambil sendiri ke perusahaan harganya juga sama.Hal ini yang menjadi pertimbangan dalam pembelian oleh konsumen.

Berdasarkan survei awal di PT Duta Megah Wisata, peneliti menemukan adanya masalah secara frekuensi pada pelayanan. Hal ini dibuktikan konsumen mengeluh diakibatkantiket pesawat terbangyang ingin dipesan konsumen yang terabaikan. Adanya sebagian karyawan perusahaan masih kurang lengkap dalam memberikan informasi produk tiket pesawat. Pelayanan yang kurang maksimal sering mengakibatkan konsumen kurang berminat dalam pembelian. Melalui kualitas layanan, karyawan dapat mewujudkan kenyamanan konsumen yang akhirnya dapat mendorong keputusan pembelian. Untuk meningkatkan penjualan perusahaan, perusahaan dapat memperhatikan strategi pemasaran, harga serta pelayanan yang diberikan untuk menarik minat konsumen dalam pembelian. Keputusan pembelian yang dilakukan konsumen dengan melibatkan pandangannya terhadap mutu, nilainya dan harga produknya.

Silitingo (2016) mendefinisikan, strategi pamasaran adalah suatu kumpulan tujuan, aturan maupun kebijakan mengarahkan perusahaan untuk menawarkan produknya sehingga perusahaan mampu menghadapi keadaan persaingan yang selalu berubah-ubah.Kemudian menurut Assauri (2018) pengertian strategi pemasaran ialah suatu cara menyeluruh dapat dijadikan panduan guna mencapai tujuan pemasaran perusahaan. Strategi pemasaran ialah cara untuk menawarkan produknya dari waktu ke waktu sehingga perusahaan mampu menghadapi keadaan persaingan yang selalu berubah-ubah. Menurut Assauri(2014) indikator strategi pemasaran sebagai berikut :Segmenting, Targeting, dan Positioning

Menurut Kasmir (2017) pelayanan ialah tindakan ataupun sikap yang memberikan kepuasan kepada pelanggannya. Johani (2017) mendefinisikan, pelayanan ialah kegiatan untuk memberikan suatu manfaat, hasil dari pelayanan berupa kepuasan menggunakan jasa maupun produk. Kualitas pelayanan dapat terwujud dari kebutuhan maupun keinginan pelanggan terpenuhi sesuai harapannya.

Berdasarkan pendapat di atas dapat disimpulkan pelayanan ialah terpenuhinya kebutuhan pelanggan secara langsung dari suatu produk yang memberikan manfaat, hasil dari pelayanan berupa kepuasan menggunakan jasa maupun produk.

Tjiptono \& Gregorius (2017) dimensi kualitas pelayanan yaitu :Reliabilitas, yakni mampu dalam melayani secara akurat, memuaskn pelanggan. Responsivitas, yaitu karyawan membantu pelanggan dengan pelayanan cepat tanggap. Jaminan yakni karyawan memiliki kemampuan, pengetahunan dan sikap mudah dipercaya yang terhindari keraguan pelanggan. Empati yakni mudah terjalin hubungan, efektif 
dalam berkomunikasi, mendapatkan perhatian dari pelanggan. Bukti fisik yakni karyawan, tersedianya fasilitas, perlengkpan dan sarana berkomunikasi.

Assauri (2018) harga ialah salah satu unsur bauran pemasaran mencakup unsur biaya. Menurut Supranto \& Limakrisna (2011) harga ialah konsumen yang membayar sejumlah uang untuk menggunakan produk. Harga ialah keseluruhan biaya dikeluarkan konsumen untuk menggunakan barang atau jasa berguna mendapatkan manfaatnya.

Menurut Hasan (2014) Indikator harga terdiri dari: Harga pokok dan diskon yang diberikan diskon harga oleh perusahaan. Syarat pembayaran dimana kesepakatan antara penjual dengan pembeli dalam pembyaran barang.Persyaratan kredit dimana perusahaan memberikan syarat kredit kepada pelanggan dalam membeli produk secara kredit.

Morissan (2012), "keputusan pembelian ialah langkah terakhir diambil konsumen dalam pembelian barang atau jasa". Sangadji et al., (2013) "Keputusan pembelian ialah sikap berdasarkan keinginan konsumen dalam memlih tindakan membeli barang atau jasa".

Berdasarkan pendapat yang telah dikemukakan, maka keputusan pembelian ialah sikap konsumen dalam memilih produk ataupun jasa kemudian melakukan pembelian produk atau jasa.

Abdullah \& Tantri (2014) "keputusan pembelian memiliki lima peranan : 1) Mencetuskan ide : pertama kali diusulkan produk atau jasa tersebut. 2) Memberikan pengaruh: pandangan konsumen dalam memutuskan pembelian. 3) Keputusan diambil: orang memutuskan untuk melakukan pengambilan putusan dalam pembelian. 4) Pembeli: orang yang terlibat dalam kegiatan membeli.5) Pemakai: orang yang mempergunakan barang ataupun jasa."

Menurut Sunyoto (2014) tiap keputusan pembelian produk harus memiliki tujuh unsur penting yaitu : 1) Keputusan atas jenis produk. Perusahaan harus memperhatikan konsumen memiliki minat beli produk sehingga adanya pertimbangkan konsumen dalam pengambilan keputusan beli barang. 2) Keputusan atas bentuk produk. Biasanya ukuran, corak maupun mutu produk sebagai pertimbangn konsumn mengambil keputusan membeli produk tersebut. 3) Keputusan atas merek. Tiap merek produk menjadi pertimbangan konsumen dalam memutuskan untuk membeli atau tidak. 4) Keputusan atas penjualnya. Konsumen biasanya akan memilih penjual produk seperti produsen, pedagang besar maupun pedagang eceran. 5) Keputusan atas jumlah produk. Konsumen dalam persiapan membeli produk selalu mempertimbangkan jumlah produk yang dibeli banyak atau sesuai kebutuhan konsumen. 6) Keputusan atas waktu pembelian. Pengambilan keputusan pembelian berkaitang dengan kapan konsumen akan membeli produk tersebut. 7) Keputusan atas pembayaran. Pengambilan keputusan pembayaran harus sesuai prosedur yang ditetapkan perusahaan.

Heri \& Sihombing (2018) strategi pamasaran merupakan cara untuk memasarkan produk, harga, distribusi dan promosi akan mempengaruhi tingkat volume penjualan. Menurut Parmana (2018) faktor penurunan jumlah pengunjung dan penjualan dari sisi bauran pemasaran yang mencakup produk, harga, tempat, dan promosi. 
Johani (2017) mengenai, harga dan pelayanan yang bersaing dipasaran bertujuan untuk meningkatkan volume penjualan, serta saling mendukung antara lainnya. Menurut Sunyoto (2014) penjual memberikan pelayanan baik maupun kurang baik dapat mempengaruhi keputusan pembelian. Menurut Kirom (2012) kualitas pelayanan ialah cara prusahaan memperbaiki mutu pelayanan yang buruk agar dapat melindungi kepentingan konsumen. Kemudian Lahindah et al., (2018) kualitas pelayanan yang baik membuat konsumen merasa nyaman sehingga konsumen akan merasa senang dan mengambil keputusan pembelian karena telah merasakan kualitas pelayanan.

Sambudi (2016) menyatakan, harga memiliki pengaruh cukup besar sehingga konsumen melakukan pembelian suatu produk. Jika harga suatu produk memiliki harga yang murah, sehingga memungkinan volume penjualannya akan semakin tinggi, dan jika harga suatu produk memiliki harga yang tinggi, sehingga memungkinkan volume penjualannya menjadi rendah. Menurut Sunyoto (2014), kepuasan tinggi meningkatkan pelanggan tetap loyal dengan meminimalkan biaya operasi, mengurangi harga sehingga mendorong pelanggan tetap membeli produk. Menurut Sudaryon (2016) harga penetrasi untuk penetapan produk baru yang dapat menarik minat beli konsumen dengan harga rendah ataupun harga mengapung tinggi berbeda dengan harga pasaran.

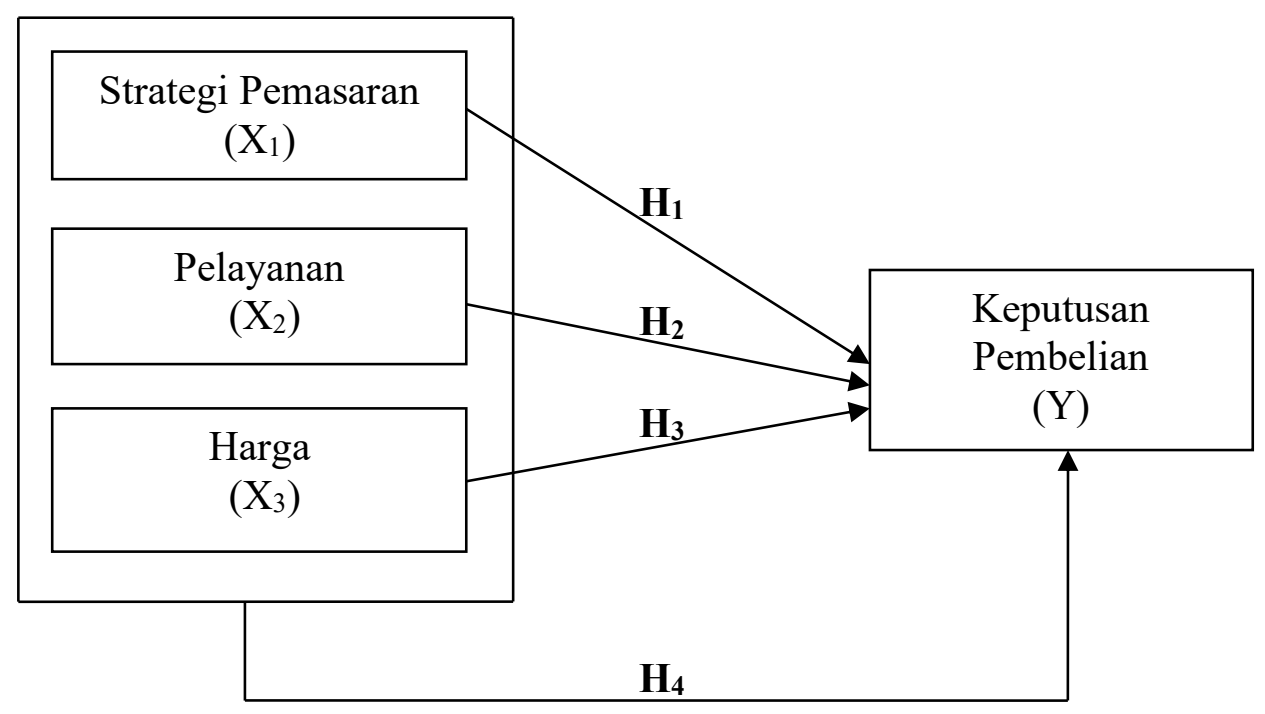

Gambar 1. Kerangka Konseptual

Hipotesis ialah pernyataan sementara atas pertanyaan rumusan masalah. Untuk itu hipotesis penlitian yaitu :

$\mathrm{H}_{1}$ : Strategi pemasaran mempengaruhi terhadap keputusan pembelian tiket pesawat terbang Pada PT Duta Megah Wisata.

$\mathrm{H}_{2}$ : Pelayanan mempengaruhi terhadap keputusan pembelian tiket pesawat terbang Pada PT Duta Megah Wisata.

$\mathrm{H}_{3}$ : Harga mempengaruhi terhadap keputusan pembelian tiket pesawat terbang Pada PT Duta Megah Wisata. 
$\mathrm{H}_{4}$ : Strategi pemasaran, pelayanaan dan harga mempengaruhi terhadap keputusan pembelian tiket pesawat terbang Pada PT Duta Megah Wisata.

\section{METODE PENELITIAN}

Tempat penelitiannya adalah PT. Duta Megah Wisata jalan Mustafa No.33, Medan Timur, Sumatera Utara 20238. Kuantitatif pendekatan penelitian untuk memperoleh alur jelas. Menurut Sugiyono (2017) penelitian kuantitatif bersifat umum dan random pengambilan populasinya maupun sampelnya. Data riset yang digunakan dalam 3264eknik pengumpulan data yaitu kuisioner dan wawancara.

Populasi adalah konsumen PT Duta Megah Wisata yang berjumlah 133 responden. Menurut Widodo (2015) rumus atau formula yang banyak digunakan adalah formula slovin bahwa batas galat (error) $1 \%, 5 \%$ atau $10 \%$ dengan rumus:

$$
\begin{aligned}
& \mathrm{n}=\frac{\mathrm{N}}{1+\mathrm{N}(\mathrm{e})^{2}} \ldots \ldots \ldots(1) \\
& \text { Dimana: } \quad \mathrm{n}=\text { Jumlah sampel } \\
& \mathrm{N}=\text { Ukuran populasi } \\
& \mathrm{e}=\text { taraf kesalahan }
\end{aligned}
$$

Berdasarkan rumus slovin dapat diketahui banyaknya sampel yang dibutuhkan:

$$
\begin{aligned}
\mathrm{n} & =\frac{133}{1+133(0,05)^{2}} \\
\mathrm{n} & =\frac{133}{1,3325} \\
\mathrm{n} & =99,8 \\
\mathrm{n} & =100
\end{aligned}
$$

Sampel penelitian ini berjumlah 100 konsumen PT Duta Megah Wisata.

Hasil pengumpulan data atas pembagian kuisioner yang dilakukan pada 100 orang konsumen PT Duta Megah Wisata yang dijadikan responden diperoleh kategori responden mengenai usia dan jenis kelamin pada tabel:

Tabel 2.

Karakteristik Responden PT Duta Megah Wisata

\begin{tabular}{llcc}
\hline No & Karakteristik Responden & Jumlah (Orang) & Persentase (\%) \\
\hline $\mathbf{1}$ & Usia & & \\
\hline & $\leq 20$ tahun & 19 & 19 \\
& $21-29$ tahun & 35 & 35 \\
& $\geq 30$ tahun & 46 & 46 \\
& Total & 100 & 100,00 \\
2 & Jenis Kelamin & & \\
\cline { 2 - 3 }
\end{tabular}

Bersambung... 
Lanjutan Tabel 2.

\begin{tabular}{llcc}
\hline No & Karakteristik Responden & Jumlah (Orang) & Persentase (\%) \\
\hline & Usia & & 52 \\
& Laki-laki & 52 & 48 \\
& Perempuan & 48 & 100,00 \\
\hline
\end{tabular}

Sumber: Data diolah, 2020

Tabel 3.

Skor Jawabannya Responden Kuisioner

\begin{tabular}{ccc}
\hline No. & Jenis Jawaban & Skor \\
\hline 1. & Sangat setuju & 5 \\
2. & Setuju & 4 \\
3. & Ragu-ragu & 3 \\
4. & Tidak setuju & 2 \\
5. & Sangat tidak setuju & 1 \\
\hline
\end{tabular}

Sumber: Sugiyono (2012:133)

Tabel 4.

Identifikasi dan Definisi Operasional Variabel Penelitian

\begin{tabular}{|c|c|c|c|c|}
\hline No & Variabel & Definisi Variabel & Indikator & Skala \\
\hline 1. & $\begin{array}{l}\text { Strategi } \\
\text { Pemasaran } \\
\left(\mathrm{X}_{1}\right)\end{array}$ & $\begin{array}{l}\text { Strategi pamasaran ialah } \\
\text { suatu serangkaian tujuan, } \\
\text { sasaran, kebijakan dan aturan } \\
\text { yang mengarahkan } \\
\text { perusahaan untuk } \\
\text { menawarkan produknya. } \\
\text { Sumber : Silitingo (2016:94) }\end{array}$ & $\begin{array}{l}\text { 1. } \quad \text { Segmenting }\left(\mathrm{X}_{1,1}\right) \\
\text { 2. } \quad \text { Targeting }\left(\mathrm{X}_{1,2}\right) \\
\text { 3. } \\
\text { Positioning }\left(\mathrm{X}_{1,3}\right) \\
\text { Sumber : Assauri }(2018: 67-69)\end{array}$ & Likert \\
\hline 2. & $\begin{array}{l}\text { Pelayanan } \\
\left(\mathrm{X}_{2}\right)\end{array}$ & $\begin{array}{l}\text { Pelayanan ialah tindakan } \\
\text { orang lain yang memberikan } \\
\text { manfaaat atas pelayann } \\
\text { berupa rasa puas setelah } \\
\text { menggunakn barang atau } \\
\text { jasa. } \\
\text { Sumber :Kasmir }(2017: 47)\end{array}$ & $\begin{array}{l}\text { 1. } \text { Reliabilitas }\left(\mathrm{X}_{2,1}\right) \\
\text { 2. } \\
\text { 3. } \text { Jaminansivitas }\left(\mathrm{X}_{2,2}\right) \\
\left.\text { 4. } \quad \text { Empati( } \mathrm{X}_{2,4}\right) \\
\text { 5. } \\
\text { Sumber })\left(\mathrm{X}_{2,3}\right) \\
\text { (2017:88-89) }\end{array}$ & Likert \\
\hline 3. & $\begin{array}{l}\text { Harga } \\
\text { (X3) }\end{array}$ & $\begin{array}{l}\text { Harga ialah bauran } \\
\text { pemasaran mendapatkan } \\
\text { pendaptan dengan biaya. } \\
\text { Sumber: Assauri (2014:223) }\end{array}$ & $\begin{array}{l}\text { 1. Harga pokok dan } \\
\text { diskon }\left(X_{3,1}\right) \\
\text { 2. Syarat pembayaran }\left(X_{3,2}\right) \\
\text { 3. Persyaratan kredit }\left(X_{3,3}\right) \\
\text { Sumber: Hasan }(2014: 72) \\
\end{array}$ & Likert \\
\hline
\end{tabular}

Bersambung... 
Lanjutan Tabel 4.

\begin{tabular}{|c|c|c|c|c|}
\hline No & Variabel & Definisi Variabel & Indikator & Skala \\
\hline 4. & $\begin{array}{l}\text { Keputusan } \\
\text { Pembelian } \\
\text { (Y) }\end{array}$ & $\begin{array}{l}\text { Keputusan pmbelian ialah } \\
\text { tindakan akhir setelah } \\
\text { memiliki niat membeli. } \\
\text { Sumber : Morissan } \\
(2012: 111)\end{array}$ & 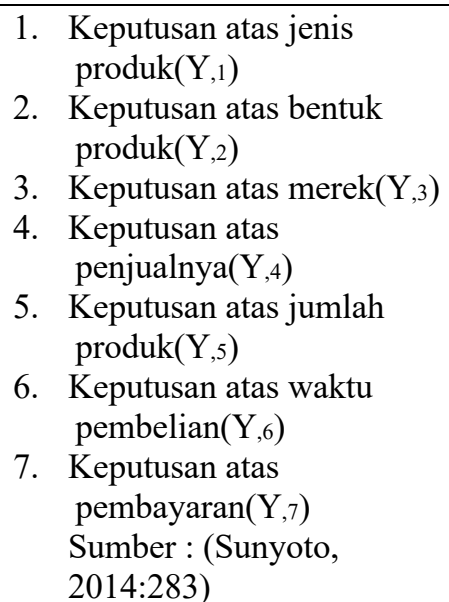 & Likert \\
\hline
\end{tabular}

Sumber: Data diolah, 2020

Data penelitian dikumpulkan dengan tekniknya berikut : Kuisioner ialah pertanyaan tertulis diberikan kepada respondennya untuk menjawabnya.

Wawancara ialah suatu percakapan pewawancara dengan terwawancara dalam mendapatkan informasi. Menurut Anwar (2016) wawancara ialah cara mengumpulkan data atas pertanyaan secara lisan terhadap subyek penelitian.

Data sekunder yang menggunakan literatur buku dan jurnal. MenurutSugiyono (2017) data primer bersumber langsung dari perusahaan. Riset ini mengumpulkan data dengan sebaran kuioner. Menurut Sugiyono (2017) sumber sekunder ialah datanya didapat secara tidak langsung. Datanya diperoleh melalui PT Duta Megah Wisata, sejarah PT Duta Megah Wisata, struktur organisasi,visi dan misi.

Riset ini menggunakan analisis regresi linear berganda. Terlebih dahulu melakukan uji asumsi klasik yang terdiri dari normalitas, multikolinieritas dan heteroskedastisitas. Kemudian, pengujian hipotesis dilakukan regresi linear berganda, uji t, uji F dan koefisien determinasi.

\section{HASIL DAN PEMBAHASAN}

Ghozali (2013), "uji validitas berguna mengukur data kuisioner tersebut valid atau tidak."(Sugiyono, 2017), data validitas kuisioner dengan persyaratan $r$ lebih besar 0,3.

Dari Tabel 5. terlihat bahwa keseluruhan pertanyaan yang diajukan berguna menguji variabel strategi pemasaran dinyatakan semuanya valid karena correction item-total correlation lebih besar dari 0,3610.

Dari Tabel 6. terlihat bahwa keseluruhan pertanyaan yang diajukan untuk menguji variabel pelayanan dinyatakan semuanya valid karena correction itemtotal correlation lebih besar dari 0,3610. 
Tabel 5.

Uji Validitas Strategi Pemasaran

\begin{tabular}{clccc}
\hline No & \multicolumn{1}{c}{ Pertanyaan } & $\begin{array}{c}\text { Corretion item } \\
\text {-total } \\
\text { correlation }\end{array}$ & $\begin{array}{c}\text { Sig (2 } \\
\text { tailed) }\end{array}$ & Keterangan \\
\hline 1. & $\begin{array}{l}\text { Bagaimana menurut Bapak/Ibu, kemudahan } \\
\text { konsumen untuk melakukan pembelian produk } \\
\text { tiket yang ditawarkan PT Duta Megah Wisata? }\end{array}$ & 0,856 & 0,000 & valid \\
2. $\begin{array}{l}\text { Bagaimana menurut Bapak/Ibu, semua } \\
\text { kalangan masyarakat dapat membeli produk } \\
\text { tiket yang ditawarkan PT Duta Megah Wisata? }\end{array}$ & 0,553 & 0,002 & valid \\
3. $\begin{array}{l}\text { Bagaimana menurut Bapak/Ibu, kemudahan } \\
\text { konsumen untuk mendapatkan infomasi atau } \\
\text { iklan PT Duta Megah Wisata? }\end{array}$ & 0,498 & 0,005 & valid \\
4. Bagaimana menurut Bapak/Ibu, seringkah \\
$\begin{array}{l}\text { Anda mendapatkan promo tiket yang } \\
\text { ditawarkan PT Duta Megah Wisata? }\end{array}$ & 0,915 & 0,000 & valid \\
Bagaimana menurut Bapak/Ibu, kesesuaian \\
produk tiket yang ditawarkan perusahan?
\end{tabular}

Sumber: Data diolah, 2020

Tabel 6.

Uji Validitas Pelayanan

\begin{tabular}{llccc}
\hline No & \multicolumn{1}{c}{ Pertanyaan } & $\begin{array}{c}\text { Corretion } \\
\text { item -total } \\
\text { correlation }\end{array}$ & $\begin{array}{c}\text { Sig (2 } \\
\text { tailed) }\end{array}$ & Keterangan \\
\hline 1. & $\begin{array}{l}\text { Bagaimana menurut Bapak/Ibu, loket penjualan } \\
\text { tiket dibuka tepat waktu? }\end{array}$ & 0,437 & 0,016 & valid \\
2. $\quad \begin{array}{l}\text { Bagaimana menurut Bapak/Ibu, keakuratan } \\
\text { informasi yang disampaikan petugas mengenai } \\
\text { jadwal keberangkatan pesawat? }\end{array}$ & 0,662 & 0,000 & valid \\
3. $\quad \begin{array}{l}\text { Bagaimana menurut Bapak/Ibu, apakah Anda } \\
\text { mudah mendapatkan layanan yang cepat dan } \\
\text { benar? }\end{array}$ & 0,771 & 0,000 & valid \\
4. $\begin{array}{l}\text { Bagaimana menurut Bapak/Ibu, kemudahan } \\
\text { Anda mendapatkan tanggapan dari petugas } \\
\text { mengenai informasi tiket? }\end{array}$ & 0,600 & 0,000 & valid \\
5agaimana menurut Bapak/Ibu, kenyamanan \\
yang diberikan perusahaan sudah baik?
\end{tabular}

Bersambung... 
Lanjutan Tabel 6.

\begin{tabular}{clccc}
\hline No & Pertanyaan & $\begin{array}{c}\text { Corretion } \\
\text { item -total } \\
\text { correlation }\end{array}$ & $\begin{array}{c}\text { Sig (2 } \\
\text { tailed) }\end{array}$ & Keterangan \\
\hline 6. & $\begin{array}{l}\text { Bagaimana menurut Bapak/Ibu, kemampuan } \\
\text { karyawan berkomunikasi dengan baik? }\end{array}$ & 0,721 & 0,000 & Valid \\
7. & $\begin{array}{l}\text { Bagaimana menurut Bapak/Ibu, Anda selalu } \\
\text { mengutamakan pelayanan konsumen? }\end{array}$ & 0,642 & 0,000 & valid \\
8. $\begin{array}{l}\text { Bagaimana menurut Bapak/Ibu, Anda } \\
\text { mendapatkan pelayanan maksimal dari petugas }\end{array}$ & 0,472 & 0,009 & valid \\
$\begin{array}{l}\text { perusahaan? } \\
\text { Bagaimana menurut Bapak/Ibu, fasilitas } \\
\text { pelayanan pengiriman (delivery service) PT }\end{array}$ & 0,647 & 0,000 & valid \\
$\begin{array}{l}\text { Duta Megah Wisata? } \\
\text { Bagaimana menurut Bapak/Ibu, tersediaanya } \\
\text { call center utnuk pemesanan tiket? }\end{array}$ & 0,777 & 0,000 & valid \\
\hline
\end{tabular}

Sumber: Data diolah, 2020

Tabel 7.

Uji Validitas Harga

\begin{tabular}{|c|c|c|c|c|}
\hline NO & Pertanyaan & $\begin{array}{l}\text { Corretion } \\
\text { item -total } \\
\text { correlation }\end{array}$ & $\begin{array}{l}\text { Sig }(2 \\
\text { tailed })\end{array}$ & Keterangan \\
\hline 1. & $\begin{array}{l}\text { Adanya pemberian diskon harga atas pembelian } \\
\text { tiket. }\end{array}$ & 0,898 & 0,000 & Valid \\
\hline 2. & $\begin{array}{l}\text { Adanya pemberian diskon tiket dalam masa } \\
\text { promo tertentu. }\end{array}$ & 0,837 & 0,000 & Valid \\
\hline 3. & $\begin{array}{l}\text { Anda selalu mengikuti syarat pembayaran yang } \\
\text { diberlakukan perusahaan. }\end{array}$ & 0,670 & 0,000 & Valid \\
\hline 4. & $\begin{array}{l}\text { Kemudahan syarat pembayaran yang diberikan } \\
\text { perusahaan. }\end{array}$ & 0,638 & 0,000 & Valid \\
\hline 5. & $\begin{array}{l}\text { Kesesuaian persyaratan kredit yang diberikan } \\
\text { perusahaan. }\end{array}$ & 0,906 & 0,000 & Valid \\
\hline 6. & $\begin{array}{l}\text { Kemampuan Anda mengikuti prosedur kredit } \\
\text { yang diberikan perusahaan. }\end{array}$ & 0,839 & 0,000 & Valid \\
\hline
\end{tabular}

Sumber: Data diolah, 2020

Dari Tabel 7. terlihat bahwa keseluruhan pertanyaan yang diajukan untuk menguji variabel harga dinyatakan semuanya valid karena correction item-total correlation lebih besar dari 0,3610 . 
Tabel 8.

Uji Validitas Keputusan Pembelian

\begin{tabular}{|c|c|c|c|c|}
\hline No & Pertanyaan & $\begin{array}{c}\text { Corretion } \\
\text { item -total } \\
\text { correlation } \\
\end{array}$ & $\begin{array}{l}\text { Sig (2 } \\
\text { tailed) }\end{array}$ & Keterangan \\
\hline 1. & $\begin{array}{l}\text { Tiket pesawat yang dijual perusahaan memiliki } \\
\text { beberapa jadwal penerbangan. }\end{array}$ & 0,648 & 0,000 & valid \\
\hline 2. & $\begin{array}{l}\text { Seberapa banyak konsumen yang membeli tiket } \\
\text { PT Duta Megah Wisata. }\end{array}$ & 0,656 & 0,000 & valid \\
\hline 3. & Kemudahan tiket dibawa kemana saja. & 0,614 & 0,000 & valid \\
\hline 4. & Ukuran tiket yang ekonomis. & 0,616 & 0,000 & valid \\
\hline 5. & $\begin{array}{l}\text { Seberapa lama Anda berlangganan tiket di } \\
\text { perusahaan. }\end{array}$ & 0,799 & 0,000 & valid \\
\hline 6. & $\begin{array}{l}\text { Kemudahan dalam mengingat PT Duta Megah } \\
\text { Wisata. }\end{array}$ & 0,713 & 0,000 & valid \\
\hline 7. & $\begin{array}{l}\text { Kesesuaian realisasi penjualan dengan target } \\
\text { penjualan sebelumnya menurut Anda. }\end{array}$ & 0,581 & 0,001 & valid \\
\hline 8. & Reputasi PT Duta Megah Wisata. & 0,637 & 0,000 & valid \\
\hline 9. & $\begin{array}{l}\text { Kesesuaian jumlah pesanan tiket Anda dengan } \\
\text { tiket yang tersedia di perusahaan. }\end{array}$ & 0,579 & 0,001 & valid \\
\hline 10. & Ketersediaan tiket pesanan Anda. & 0,598 & 0,000 & valid \\
\hline 11. & $\begin{array}{l}\text { Melakukan pembelian produk berulang-ulang } \\
\text { atau lebih dari satu kali dalam setahun. }\end{array}$ & 0,480 & 0,007 & valid \\
\hline 12. & Ketepatan waktu pengiriman tiket pesanan. & 0,637 & 0,000 & valid \\
\hline 13. & $\begin{array}{l}\text { Kemudahan yang diberikan perusahaan atas } \\
\text { pembayaran produk tiket. }\end{array}$ & 0,414 & 0,023 & valid \\
\hline 14. & $\begin{array}{l}\text { Kemudahan sistem pembayaran produk tiket di } \\
\text { PT Duta Megah Wisata. }\end{array}$ & 0,799 & 0,000 & valid \\
\hline
\end{tabular}

Sumber: Data diolah, 2020

Setyono et al. (2007), pengukuran uji reliabilitas dengan ketentuan: Jika Cronbach's alphanya $<0,6$ (reliabilitas buruk). Jika Cronbach's alphanya 0,6-0,79 (reliabilitas diterima). Jika Cronbach's alphanya 0,8 (reliabilitas baik). Ghozali (2013), reliabel digunakan untuk mengukur jawaban data kuisioner stabil dari waktu ke waktu. 
Dari Tabel 8. di atas, strategi pemasaran nilai realibilitas 0,836 , pelayanan sebesar 0,841 , harga sebesar 0,891 dan keputusan pembeliannya sebesar 0,882 disimpulkan reliabel dengan Cronbachs Alpha>0,70.

Tabel 9.

Uji Reliabilitas Variabel

\begin{tabular}{cccc}
\hline Variabel & Cronbach's Alpha & N of Item & Keterangan \\
\hline Strategi Pemasaran & 0,836 & 6 & \\
Pelayanan & 0,841 & 10 & Reliabel \\
Harga & 0,891 & 6 & Reliabel \\
Keputusan Pembelian & 0,882 & 14 & Reliabel \\
\hline Sumber: Data diolah, 2020 & & &
\end{tabular}

Tabel 10.

Deskriptif Statistik

Descriptive Statistics

\begin{tabular}{lrrrrr}
\hline \multicolumn{7}{c}{ Descriptive Statistics } \\
\hline & N & \multicolumn{1}{c}{ Minimum } & Maximum & Mean & Std. Deviation \\
\hline Strategi Pemasaran & 100 & 13.00 & 30.00 & 21.3700 & 3.42202 \\
Pelayanan & 100 & 25.00 & 48.00 & 35.1700 & 5.41426 \\
Harga & 100 & 13.00 & 29.00 & 21.7400 & 3.79425 \\
Keputusan Pembelian & 100 & 33.00 & 66.00 & 50.1800 & 7.07018 \\
Valid N (listwise) & 100 & & & &
\end{tabular}

Jumlah responden strategi pemasaran $\left(\mathrm{X}_{1}\right) 100$ orang, nilai mean 21,3700satuan, min. 13,00 satuan, max 30,00 satuan dan std. deviasi 3,42202satuan. Jumlah responden pelayanan $\left(\mathrm{X}_{2}\right) 100$ orang, nilai mean 35,1700satuan, min. 25,00 satuan, max 48,00 satuan dan std. deviasi 5,41426satuan. Jumlah responden harga $\left(\mathrm{X}_{3}\right) 100$ orang, nilai mean 21,7400satuan, min. 13,00 satuan, max 29,00 satuan dan std. deviasi 3,79425satuan. Jumlah responden keputusan pembelian (Y)100 orang, nilai mean 50,1800 satuan, min. 33,00 satuan, max 66,00 satuan dan std. deviasi 7,07018 satuan.

Pertama kali, melakukan asumsi klasik terlebih dahaluhu sebelum melakukan uji hipotesis. Asumsi klasik berupa normalitas, multikolinieritas dan heteroskedastisitas.Normalitas data yang bertujuannyadiketahui data terdistribusi dengan normal atau tidak. Normalitasdapat berupa grafik, Normal P-plot Regression Standardized dan Kolmogrov-Smirnov (K-S).

Hipotesis: Data tersebar didekat garis diagonal dengan ikut garis diagonal menunjukkan normal.Data tersebar jauh dari garis diagonal dengan bukan ikut garis diagonal menunjukkan data tidak normal.

Data strategi pemasaran, pelayanan, harga dan kputusan pmbelian berdistribusi normal dengan bentuk grafik histogram menunjukkan berbentuk lonceng dan tidak mengalami kemencengan. Diagram Normal P-plot Rgression Standardized, untuk melihat apakah berdistribusi normal atau tidak. 


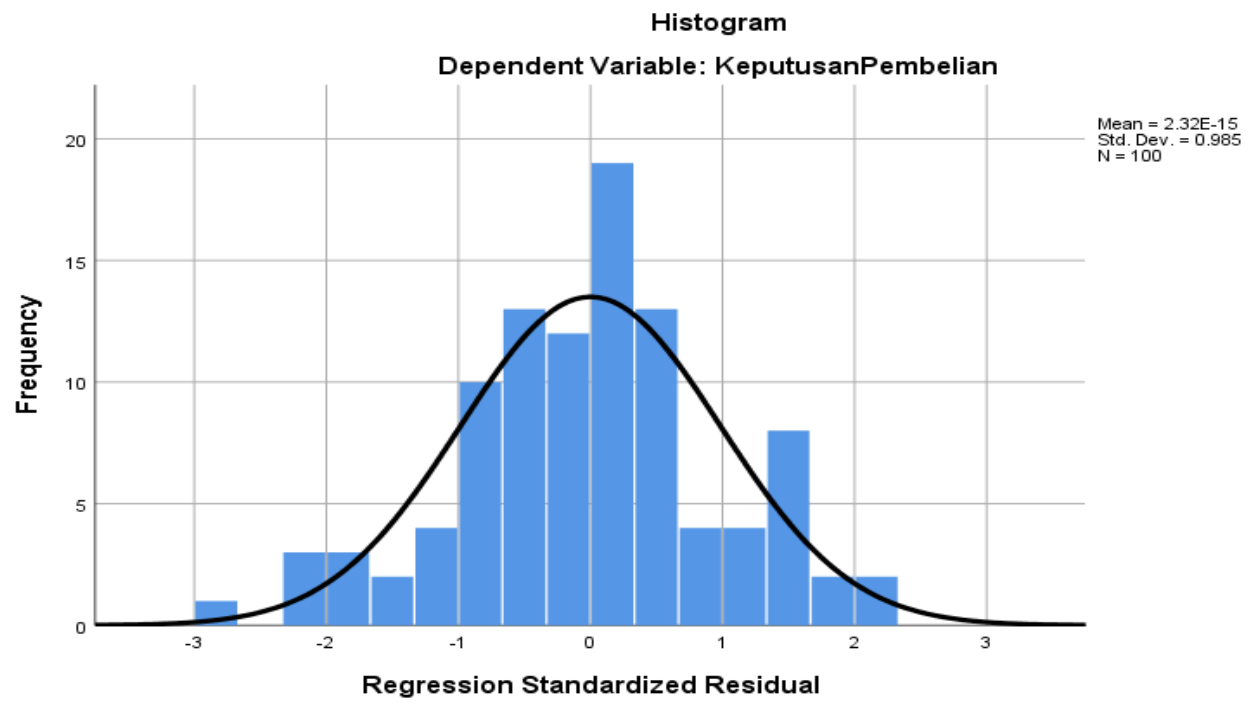

Gambar 2. Histogram

Sumber: Data diolah, 2020

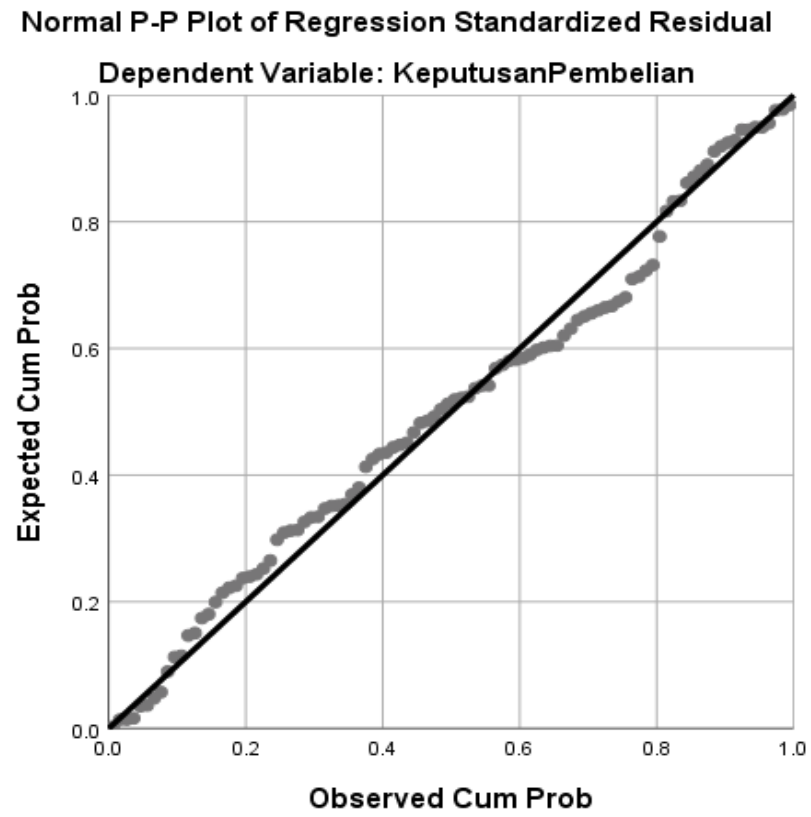

Gambar 3.Normal P-P Plot of Regression Standardized Residual Sumber: Data diolah, 2020

Titik pada Normal P-plot Regression Standardized mengikuti garis diagonal menunjukkan data normal. Analisis normalitas statistik pada one Kolmogorov Smirnovuntuk mengetahui data normal atau tidak.

Menentukan ketentuan keputusan: Asymp sig berada di atas 0,05 data normal, Asymp sig berada dibawah 0,05 data tidak normal. 
Tabel 11.

One-Sample Kolmogorov-Smirnov Test

\begin{tabular}{|c|c|c|}
\hline & & Unstandardized Residual \\
\hline $\mathrm{N}$ & \multirow{8}{*}{$\begin{array}{l}\text { Mean } \\
\text { Std. Deviation } \\
\text { Absolute } \\
\text { Positive } \\
\text { Negative }\end{array}$} & 100 \\
\hline \multirow[t]{2}{*}{ Normal Parameters ${ }^{\mathrm{a}, \mathrm{b}}$} & & .0000000 \\
\hline & & 2.64732222 \\
\hline \multirow[t]{3}{*}{ Most Extreme Differences } & & .077 \\
\hline & & .077 \\
\hline & & -.056 \\
\hline Test Statistic & & .077 \\
\hline Asymp. Sig. (2-tailed) & & $.153^{\mathrm{c}}$ \\
\hline
\end{tabular}

Nilai sig. berada diatas $0,05(5 \%)$ maka terdistribusi data normal yang terlihat dari Asymp. sig. (2-tailed) menunjukkan bahwa strategi pemasaran, pelayanan, harga dan keputusan pembelian sebesar $0,153>0,05$.

Multikolinieritas sebagai pengujian regresi ada tidaknya korelasi antar variabel bebas. Biasanya dengan syarat nilai Tolerance $\leq 0,10$ dan nilai VIF $>10$. Pengujian multikolinearitas disajikan :

Tabel 12.

Uji Multikolinieritas

\begin{tabular}{llcc}
\hline & & \multicolumn{2}{c}{ Collinearity Statistics } \\
\cline { 3 - 4 } Model & & Tolerance & VIF \\
\hline 1 & (Constant) & .566 & 1.766 \\
& Strategi Pemasaran & .537 & 1.864 \\
& Pelayanan & .366 & 2.734 \\
& Harga & &
\end{tabular}

Sumber: Data diolah, 2020

Strategi pemasaran dengan tolerance sebesar 0,566 , pelayanan tolerance sebesar 0,537 , harga dengan tolerance $0,366>0,1$ dan VIF untuk strategi pemasaran 1,766, VIF untuk pelayanan sebesar 1,864, VIF untuk harga sebesar 2,734< 10 dikatakan tidak ada gejala multikolinieritas.

Heteroskedastistas dengan melihat scatterplot yang tidak berpola berada di sumbu X dan Y tersebar acak di bawah angka 0. Hasilnya terlihat pada Gambar 4.

Grafik Scatterplot memiliki titik menyebar acak dan tidak berpola maka tidak ada heteroskedastisitasnya.

Nilai probabilitas (sig.) pada Tabel 13. untuk variabel strategi pemasaran 0,131 ; sig. untuk pelayanan 0,296 dan sig. untuk harga $0,136>0,05$ bahwa tidak terjadi heteroskedastisitasnya.

Regresi linear berganda memiliki persamaan:

Keputusan Pembelian $=3,603+0,399$ Strategi Pemasaran $+0,612$ Pelayanan dan 0,760 Harga. 


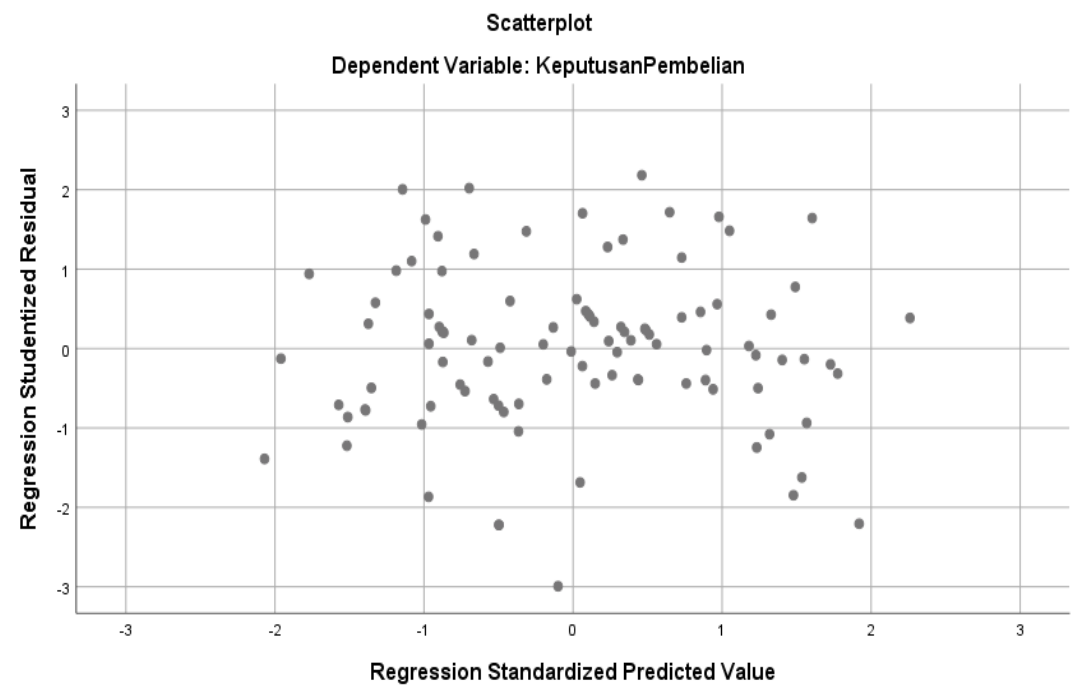

Gambar 4. Uji scatterplot

Sumber: Data diolah, 2020

Tabel 13.

Hasil Uji Glejser

\begin{tabular}{|c|c|c|c|c|c|c|}
\hline \multicolumn{7}{|c|}{ Coefficients ${ }^{\mathrm{a}}$} \\
\hline & & $\begin{array}{r}\text { Unstanc } \\
\text { Coeff }\end{array}$ & $\begin{array}{l}\text { rdized } \\
\text { ents }\end{array}$ & $\begin{array}{c}\text { Standardize } \\
d \\
\text { Coefficients }\end{array}$ & & \\
\hline \multicolumn{2}{|c|}{ Model } & B & Std. Error & Beta & $\mathbf{T}$ & Sig. \\
\hline \multirow[t]{4}{*}{1} & (Constant) & 3.745 & 1.428 & & 2.622 & .010 \\
\hline & StrategiPemasaran & -.091 & .065 & -.201 & -1.397 & .166 \\
\hline & Pelayanan & -.045 & .044 & -.139 & -1.014 & .313 \\
\hline & Harga & .117 & .077 & .254 & 1.532 & .129 \\
\hline
\end{tabular}

Sumber: Data diolah, 2020

Tabel 14.

Analisis Regresi Berganda

\begin{tabular}{|c|c|c|c|c|c|c|}
\hline \multicolumn{7}{|c|}{ Coefficients $^{\mathrm{a}}$} \\
\hline & & $\begin{array}{l}\text { Unstand } \\
\text { Coeff }\end{array}$ & $\begin{array}{l}\text { ardized } \\
\text { ients }\end{array}$ & $\begin{array}{c}\text { Standardize } \\
\text { d } \\
\text { Coefficients }\end{array}$ & & \\
\hline \multicolumn{2}{|c|}{ Model } & B & Std. Error & Beta & $\mathbf{t}$ & Sig. \\
\hline \multirow[t]{5}{*}{1} & (Constant) & 3.603 & 2.076 & & 1.735 & .086 \\
\hline & Strategi & .399 & .105 & .193 & 3.801 & .000 \\
\hline & Pemasaran & & & & & \\
\hline & Pelayanan & .612 & .068 & .469 & 8.988 & .000 \\
\hline & Harga & .760 & .118 & .408 & 6.453 & .000 \\
\hline
\end{tabular}

Nilai konstanta (a) $=3,603$ berarti strategi pemasaran, pelayanan dan harganilainyanol maka keputusan pembeliantetap sebesar 3,603. Nilai koefisien 
variabel strategi pemasaran $\left(b_{1}\right)=0,399$, nilainya positif berarti tiap penambahan satu-satuan strategi pemasaran $\left(\mathrm{X}_{1}\right)$ mengakibatkan keputusan pembelian naik 0,399 satuan.Nilai koefisien variabel pelayanan $\left(b_{2}\right)=0,612$ nilainya positif berarti tiap penambahan satu-satuan pelayanan $\left(\mathrm{X}_{2}\right)$ mengakibatkan keputusan pembeliannaik 0,612 satuan. Nilai koefisien variabel harga $\left(b_{3}\right)=0,760$ nilainya positif berarti tiap penambahan satu-satuan harga $\left(\mathrm{X}_{3}\right)$ mengakibatkan keputusan pembelian naik 0,760 satuan. Koefisien determinasinya memperlihatkn kemampuan pengaruh semakin kuat atau tidak. Jika kuat mendekati 1. Koefisien determinasi terlihat :

Tabel 15.

Hasil Pengujian Koefisien Determinasi

\begin{tabular}{lcccc}
\hline \multicolumn{5}{c}{ Model Summary } \\
\hline Model & $\mathrm{R}$ & R Square & $\begin{array}{c}\text { Adjusted R } \\
\text { Square }\end{array}$ & $\begin{array}{c}\text { Std. Error of the } \\
\text { Estimate }\end{array}$ \\
\hline 1 & $.927^{\mathrm{a}}$ & .860 & .855 & 2.68837 \\
\hline
\end{tabular}

Sumber: Data diolah, 2020

Adjusted $R$ Square 0,855 atau $85,5 \%$ berarti keputusan pembelian dijelaskan variabel bebas namun sisanya $14,5 \%$ dijalaskan variabel lain tidak diteliti seperti kualitas produk, promosi dan personal selling.

Menurut Ghozali (2013:98), "uji F menunjukkan pengaruh secara bersama variabel bebas mempengaruhi variabel terikat". Hipotesisnya $: \mathrm{H}_{0}: \mathrm{b}_{1}=\mathrm{b}_{2}=\mathrm{b}_{3}=0$, bermakna strategi pemasaran, pelayanan dan harga tidak mempengaruhi secara serempak terhadap keputusan pembelian tiket pesawat terbang Pada PT Duta Megah Wisata. $\mathrm{H}_{1}: \mathrm{b}_{1}=\mathrm{b}_{2}=\mathrm{b}_{3} \neq 0$, bermakna Strategi pemasaran, pelayanan dan harga mempengaruhi secara serempak terhadap keputusan pembelian tiket pesawat terbang Pada PT Duta Megah Wisata.

Tabel 16.

\begin{tabular}{llrrrrr}
\hline \multicolumn{7}{c}{ Hasil Uji-F } \\
\hline Model & & Sum of Squares & \multicolumn{1}{c}{ Df } & Mean Square & \multicolumn{1}{c}{ F } & Sig. \\
\hline 1 & Regression & 4254.937 & 3 & 1418.312 & 196.243 & $.000^{\mathrm{b}}$ \\
& Residual & 693.823 & 96 & 7.227 & & \\
& Total & 4948.760 & 99 & & & \\
\hline
\end{tabular}

Sumber: Data diolah, 2020

Nilai $F_{\text {hitung }}>F_{\text {Tabel }}(196,243>2,70)$ dengan sig. $0,000<0,05$ bahwa hipotesis $\mathrm{H}_{0}$ ditolak dan $\mathrm{H}_{1}$ diterima, berarti strategi pemasaran, pelayanan dan harga mempengaruhi secara bersama terhadap keputusan pembelian tiket pesawat terbang Pada PT Duta Megah Wisata.

Hipotesisnya dapat dijabarkan Jika $\mathrm{H}_{0}: \mathrm{b}_{1}, \mathrm{~b}_{2}=0$, berarti strategi pemasaran, pelayanan dan harga tidak mempengaruhi secara parsial terhadap keputusan pembelian tiket pesawat terbang Pada PT Duta Megah Wisata. Jika $\mathrm{H}_{1}: \mathrm{b}_{1}, \mathrm{~b}_{2} \neq 0$, berarti strategi pemasaran, pelayanan dan harga mempengaruhi secara parsial terhadap keputusan pmbelian tiket pesawat terbang Pada PT Duta Megah Wisata. 
Kriteria keputusan :

1. $\mathrm{H}_{0}$ diterima jika $\mathrm{t}_{\text {hitung }} \leq \mathrm{t}$ Tabel pada $\alpha=5 \%$.

2. $\mathrm{H}_{1}$ diterima jika $\mathrm{t}_{\text {hitung }}>\mathrm{t}$ Tabel pada $\alpha=5 \%$. $\mathrm{df}=\mathrm{n}-\mathrm{k}, \mathrm{df}=100-3=97$. nilai $\mathrm{t}_{\text {Tabel }}$ adalah $\mathrm{t} 5 \%$ atau $\mathrm{t}_{0,05}(97)=1,984$.

Tabel 17.

Hasil Uji t

\begin{tabular}{|c|c|c|c|c|c|c|}
\hline \multicolumn{7}{|c|}{ Coefficients $^{\mathrm{a}}$} \\
\hline \multirow{2}{*}{\multicolumn{2}{|c|}{ Model }} & \multicolumn{2}{|c|}{$\begin{array}{l}\text { Unstandardized } \\
\text { Coefficients }\end{array}$} & \multirow{2}{*}{$\begin{array}{c}\text { Standardized } \\
\text { Coefficients } \\
\text { Beta } \\
\end{array}$} & \multirow[b]{2}{*}{$\mathbf{t}$} & \multirow[b]{2}{*}{ Sig. } \\
\hline & & B & Std. Error & & & \\
\hline 1 & (Constant) & 3.603 & 2.076 & & 1.735 & .086 \\
\hline & Strategi Pemasaran & .399 & .105 & 193 & 3.801 & .000 \\
\hline & Pelayanan & .612 & .068 & .469 & 8.988 & .000 \\
\hline & Harga & .760 & .118 & .408 & 6.453 & .000 \\
\hline
\end{tabular}

Sumber: Data diolah, 2020

Pengujian uji $t$ dapat diuraikan : Nilai thitung strategi pemasaran $\left(\mathrm{X}_{1}\right)$ sebesar 3,801 berpengaruh positif dan sig. sebesar $0,000(0,000<0,05)$. Hipotesis $\mathrm{H}_{0}$ ditolak dan $\mathrm{H}_{1}$ diterima karena $t_{\text {hitung }}>\mathrm{t}_{\text {Tabel }}(3,801>1,984)$ Strategi pemasaran berpengaruh positif terhadap keputusan pembelian tiket pesawat terbang pada PT Duta Megah

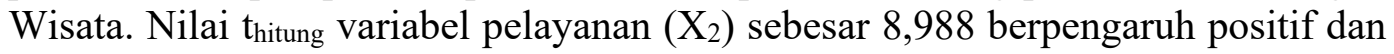
sig. sebesar $0,000(0,000<0,05)$. Hipotesis $\mathrm{H}_{0}$ ditolak dan $\mathrm{H}_{1}$ diterima karena $t_{\text {hitung }}>\mathrm{t}_{\text {Tabel }}(8,988>1,984)$. Pelayanan berpengaruh positif terhadap kputusan pmbelian tiket pesawat terbang pada PT Duta Megah Wisata. Nilai thitung variabel harga $\left(\mathrm{X}_{3}\right)$ sebesar 6,453 berpengaruh positif dan sig. sebesar $0,000(0,000<0,05)$. Hipotesis $\mathrm{H}_{0}$ ditolak dan $\mathrm{H}_{1}$ diterima karena $\mathrm{t}_{\text {hitung }}>\mathrm{t}_{\text {Tabel }}(6,453>1,984)$ harga berpengaruh positif terhadap keputusan pembelian tiket pesawat terbang pada PT Duta Megah Wisata.

Hasil penelitian ini memperlihatkan strategi pemasaran berpengaruh dan signifikan terhadap keputusan pembelian tiket pesawat terbang Pada PT Duta Megah Wisata dengan $t_{\text {hitung }}>\mathrm{t}_{\text {Tabel }}(3,801>1,984)$ dan $0,000 \quad(0,000<0,05)$ hipotesisnya $\mathrm{H}_{1}$ diterima.

Hasil penelitian sesuai dengan teori Heri \& Sihombing (2018)strategi pemasaran merupakan strategi bauran pemasaran terdiri dari produk, harga, distribusi dan promosi akan mempengaruhi tingkat volume penjualan.

Hasil penelitian ini memperlihatkan pelayanannya berpengaruh dan signifikan terhadap keputusan pmbelian tiket pesawat terbang Pada PT Duta Megah Wisata dengan $\mathrm{t}_{\text {hitung }}>\mathrm{t}_{\text {Tabel }}(8,988>1,984)$ dan $0,000(0,000<0,05)$ hipotesisnya $\mathrm{H}_{1}$ diterima.

Hasil penelitian ini sesuai dengan Johani (2017) mengenai, harga dan pelayanan yang bersaing dipasaran bertujuan untuk meningkatkan volume penjualan, serta saling mendukung antara lainnya.

Hasil penelitian ini memperlihatkan harganya berpengaruh dan signifikan terhadap keputusan pembelian tiket pesawat terbang pada PT Duta Megah Wisata dengan $\mathrm{t}_{\text {hitung }}>\mathrm{t}_{\text {Tabel }}(6,453>1,984)$ dan $0,000(0,000<0,05)$ hipotesisnya $\mathrm{H}_{1}$ diterima. 
Hasil penelitian ini sesuai dengan Sambudi (2016), harga memiliki pengaruh cukup besar sehingga konsumen melakukan pembelian suatu produk. Jika harga suatu produk memiliki harga yang murah, sehingga memungkinan volume penjualannya akan semakin tinggi, dan jika harga suatu produk memiliki harga yang tinggi, sehingga memungkinkan volume penjualannya menjadi rendah Hasil penelitian sejalan penelitian Ghanimata dan Kamal (2012) hasilnya, harga secara positif mempengaruhi terhadap keputusan pembeliannya.

\section{SIMPULAN}

Simpulan pada penelitian ini yaitu strategi pemasaran positif terhadap keputusan pembelian tiket pesawat terbang pada PT Duta Megah Wisata dengan $\mathrm{t}_{\text {hitung }}>\mathrm{t}_{\text {Tabel }}(3,801>1,984)$ dan $0,000(0,000<0,05)$ hipotesisnya $\mathrm{H}_{1}$ diterima. Pelayanannya berpengaruh positif terhadap keputusan pembelian tiket pesawat terbang pada PT Duta Megah Wisata dengan $t_{\text {hitung }}>t_{\text {Tabel }}(8,988>1,984)$ dan 0,000 $(0,000<0,05)$ hipotesisnya $\mathrm{H}_{1}$ diterima. Harganya berpengaruh positif terhadap keputusan pembelian tiket pesawat terbang pada PT Duta Megah Wisata dengan $t_{\text {hitung }}>\mathrm{t}_{\text {Tabel }}(6,453>1,984)$ dan $0,000(0,000<0,05)$ hipotesisnya $\mathrm{H}_{1}$ diterima. Strategi pemasaran, pelayanan dan harga berpengaruh secara serempak terhadap keputusan pembelian tiket pesawat terbang pada PT Duta Megah Wisata dengan nilai nilai $\mathrm{F}_{\text {hitung }}>\mathrm{F}_{\text {Tabel }}(181,395>2,70)$ dengan sig. $0,000<0,05$.

Saran pada penelitian ini yaitu, perusahaan sebaiknya menerapakan strategi pemasarannya yang efektif dalam meningkatkan keputusan pembelian produk. Pihak manajemen harus memberikan pelayanan yang terbaik dan perusahaan memonitori harga agar tidak terlalu tinggi, sehingga mampu mendorong pencapaian keputusan pembelian tinggi. Hasil penelitian dapat menjadi bahan referensi untuk meneliti pengaruh keputusan pmbelian produk.Sebaiknya hasil penelitian ini mampu menambah karya ilmiah Universitas Prima Indonesia bermanfaat bagi mahasiswa-mahasiswi lainnya.

\section{REFERENSI}

Abdullah, T., \& Tantri, F. (2014). Manajemen Pemasaran. Jakarta : Penerbti PT Raja Grafindo Persada.

Anwar, S. (2016). Metodologi Penelitian Bisnis. Jakarta: Salemba Empat. In IOSR Journal of Economics and Finance. https://doi.org/10.3929/ethz-b-000238666

Assauri, S. (2014). Manajemen Pemasaran. Jakarta : PT. Raja Grafindo Persada.

Assauri, S. (2018). Manajemen Bisnis Pemasaran. Depok: PT. RajagraGrafindo Persada.

Ghozali, I. (2013). Aplikasi Analisis Multi variate Dengan Program IBM SPSS 21. Jakarta : Penerbit Universitas Diponegoro. 
Hasan, A. (2014). Marketing dan Kasus-kasus pilihan. Yogyakarta : Penerbit Caps.

Heri, \& Sihombing. (2018). Analisis Pengaruh Dimensi Marketing Mix Terhadap Volume Penjualan Sepeda Motor Honda (Studi pada PT. Capella Dinamik NusantaraRiau). Jurnal Inovasi Bisnis Dan Manajemen Indonesia, 1(3).

Johani. (2017). Pengaruh Harga, PromosiDan Pelayanan Terhadap Volume Penjualan ada Koperasi Ikada Daihatsu Juanda Cabang Samarinda Tahun 2013-2016. EJournalAdministrasiBisnis, 5(3).

Kasmir. (2017). Customer Services Excellent Teori dan Praktik. Jakarta : Penerbti PT RajaGrafindo Persada.

Kirom. (2012). Mengukur Kinerja Pelayanan dan Kepuasan Konsumen. Cetakan Ketiga. Bandung : Penerbit Pustaka Reka Cipta.

Lahindah, Laura, Merisa, \& Rianty, A. S. (2018). The Influence of Product Innovation and Service Quality to Buying Decision and the Impact to Repeat Buying at Progo Road Bandung. The Asian Journal of Technology Management, 11(2).

Morissan. (2012). Periklanan Komunikasi Pemasaran Terpadu. Jakarta : Kencana.

Parmana. (2018). The Influence of Marketing Mix Factors In Purchasing Decision for Wooden Furniture Case of Furnimart Bogor. Indonesian Journal of Business and Entrepreneurship, 5(1).

Sambudi. (2016). Strategi Harga Dalam Meningkatkan Volume Penjualan Telur Ayam Ras Pada CV. Do'a Ibu Banjar baru. Harati, 7(13).

Sangadji, Etta, M., \& Sopiah. (2013). Perilaku Konsumen. Yogyakarta : Penerbit Andi.

Setyono, A., Rahardjo, M., Nugraheni, R., \& Rahardja, E. (2007). Analisis FaktorFaktor Yang Mempengaruhi Kerja Dan Kinerja Salesman ( Studi Kasus Pada Pt . Adira Finance Cabang Bangkong Semarang ). Jurnal Studi Manajemen \& Organisasi, 4(2), 70-80.

Silitingo. (2016). Pengaruh Strategi Pemasaran Terhadap Volume Penjualan Pada PT. Kimia Farma Trading \& Distribution.

Sugiyono. (2017). Metode Penelitian Bisnis (Pendekatan Kuantitatif, Kualitatif, Kombinasi dan R\&DSugiyono. (2017). Metode Penelitian Bisnis (Pendekatan Kuantitatif, Kualitatif, Kombinasi dan R\&D). In Metodelogi Penelitian.). In Metodelogi Penelitian. 
Sunyoto, Dadang. (2014). Dasar-Dasar Manajemen Pemasaran. Yogyakarta: CAPS.

Sunyoto, Danang. (2014). Dasar-dasar Manajemen Pemasaran. Cetakan Pertama. Yogyakarta : Penerbit PT Caps.

Supranto, \& Limakrisna. (2011). Perilaku Konsumen dan Strategi Pemasaran. Jakarta : Mitra Wacana Media.

Tjiptono, F., \& Gregorius, C. (2017). Pemasaran Strategik Mengupas Pemasaran Strategik, Branding Strategy, Customer Satisfaction, Strategi Kompetitif, hingga e-Marketing. Edisi 3. Yogyakarta : Andi.

Widodo. (2015). Metodologi Penelitian. Jakarta: Penerbit PT RajaGrafindo Persada. 